\title{
Desafios da Etnografia com Jovens em Situação de Rua: A Entrada em Campo
}

\author{
Chalenges of Ethnograpy with Street Children: Access
}

\author{
Hugo Juliano Duarte Matias*, ${ }^{*}$ \& Rosângela Francischini ${ }^{b}$ \\ ${ }^{a}$ Universidade de Brasília \& ${ }^{b}$ Universidade Federal do Rio Grande do Norte
}

\begin{abstract}
Resumo
Recentemente, a pesquisa com jovens em situação de rua tem dedicado mais atenção aos processos de socialização que estruturam seu cotidiano, aos sentidos de suas práticas sociais, levando à necessidade de novos métodos, dentre os quais a alternativa etnográfica. Relata-se aqui o processo de entrada em campo numa pesquisa etnográfica - realizada em Natal-RN, com grupo de pessoas em situação de rua (aproximadamente 11), jovens, a maioria com idade entre 16-18 anos -, para destacar a complexidade desse processo. Sua negociação determina muitos deslocamentos e exige flexibilidade do pesquisador, sob várias demandas de formas de participação e envolvimento junto ao grupo. Negociações de sentido, nessas situações, constituem desafio à pesquisa etnográfica com essa população; também novas possibilidades de invenção técnica e experiência ética.

Palavras-chave: Jovens em situação de rua; Etnografia; Entrada em campo; Ética.
\end{abstract}

\begin{abstract}
Abstratc
Recently, researches with street children have dedicated more attention to the socialization processes which structure their daily lives and to the meaning of their social practices, leading to the need of new methods as the ethnographic alternative, for instance. This paper reports the field access process occurred in an ethnographic research - performed with a group of about 11 street children, aged between 16 and 18 years old - in order to emphasize the complexity of that process. The access negotiation determines many displacements and requires researcher's flexibility, under several demands concerning the form of participation and involvement with the group. Negotiations of meaning, in such situations, are a challenge for ethnographic researches done with the mentioned population, besides offering new opportunities for technical invention and ethics experience.

Keywords: Street children; Ethnography; Access; Ethics.
\end{abstract}

O espaço das ruas é um dos elementos mais diversos entre os que povoam o imaginário popular de qualquer sociedade urbana, tornado objeto de múltiplos processos de significação, e como tal, também um ambiente muito rico nas possibilidades experienciais que oferece. Entre essas possibilidades, há muito tempo é conhecida aquela em que as pessoas tornam a rua o lugar onde vivem ou passam a maior parte de seu tempo, o que tem sido visto como algo nocivo às sociedades. A rejeição da presença de jovens nas ruas é um índice disso.

\footnotetext{
* Endereço para correspondência: Caixa Postal 112, CEP 44380-000 Cruz das Almas, BA, Brasil. E-mail: hugo_jdm@yahoo.com.br

É parte da Dissertação de Mestrado defendida pelo primeiro autor no Programa de Pós-Graduação em Psicologia da Universidade Federal do Rio Grande do Norte (UFRN), em fevereiro de 2008, cujo título é "Identidade, espaço e tempo: Negociações de sentido com a 'gente de rua". Os autores agradecem: à Coordenação de Aperfeiçoamento de Pessoal de Nível Superior (CAPES), pela bolsa de mestrado para o primeiro autor, e ao Prof. Dr. Luiz Assunção, do Departamento de Antropologia da UFRN, por variadas formas de contribuição ao projeto de pesquisa do qual este relato é parte.
}

Desde o início da década de 80, a presença de jovens e crianças nas ruas das grandes cidades tem sido investigada sob a demanda de conhecimento para a produção de políticas públicas, para dar solução a esse problema. $\mathrm{O}$ tema central e caracterizador desses estudos relacionou-se, até meados da década de 90 , com a suposição de que crianças e jovens em situação de rua estariam fora de um padrão de vida ou de condições desenvolvimentais normais, condição presumidamente provocada pela desorganização e desagregação familiar comum entre as classes mais pobres. Essa mesma demanda social de conhecimento levou diversas organizações internacionais a um ímpeto investigativo que produziu estimativas exageradas para o número de jovens e crianças em situação de rua. Muitos pesquisadores, numa avaliação posterior dessas contagens, atribuíram sua variação e inconsistência a problemas conceituais e metodológicos (Aptekar, 1996; Carrizosa \& Poertner, 1992; Lusk, 1992). Segundo Rosemberg (1993), diversos prejuízos podem ser contabilizados nesse período, como a homogeneização indevida das condições de existência dessas pessoas e o super-dimensionamento de programas assistenciais. Conforme) Aptekar e 
Abebe (1997), a hostilidade contra essa população, por parte da sociedade, é efeito justamente de sua imagem homogênea, negativa e exagerada, instruída por tais informações distorcidas.

Mais recentemente, no entanto, vem se constituindo entre pesquisadores, um consenso em torno da importância de compreensão desse fenômeno segundo a complexidade de suas características, e da importância dos determinantes histórico-culturais de suas reais condições de vida. A pesquisa etnográfica tem se mostrado cada vez mais adequada a esse propósito. Neste artigo, se pretende argumentar em favor da necessidade de estudos etnográficos com essa população; oferecer também um relato parcial de pesquisa etnográfica com jovens em situação de rua; enfatizar o processo de "entrada no campo" como condição para a realização de pesquisas como essa; e destacar a importância do manejo na negociação dessa entrada no interior das práticas sociais estruturadas que o ambiente da rua comporta.

\section{O Estudo da Socialização de Jovens na Rua e o Método Etnográfico}

O interesse pela situação de rua como algo situado histórica, social e culturalmente tem sua origem na apreciação de pesquisas a respeito das mais variadas explicações etiológicas para o fenômeno das "crianças de rua", ainda devedoras desse pressuposto da desagregação familiar. Contra as intuições de parcela ampla da sociedade brasileira, tais estudos mostraram que crianças e jovens não estão na rua somente por haverem sido abandonados, mas que, em sua maioria, têm família e mantêm vínculo regular com ela, e que somente algo em torno de $10 \%$ deles passam todo o seu tempo na rua (Rizzini \& Lusk, 1995). Outra hipótese etiológica relacionava a situação de rua com fenômenos migratórios, mas não se sustentou diante de estudos empíricos, na importância que lhe era atribuída (Juárez, 1996; Rosa, Borba, \& Ebrahim, 1992). Por fim, diversos outros fatores explicavam parcialmente a presença de jovens nas ruas. Alguns estudos apontaram a pobreza como o fator de maior importância etiológica, juntamente com o tamanho das famílias e a grande proporção dessas famílias chefiadas por mulheres (Abdelgalil, Gurgel, Theobald, \& Cuevas, 2004; Barros \& Mendonça, 1996; Juárez, 1996; Lusk, 1992; Paludo \& Koller, 2008; Rizzini \& Lusk, 1995; Rosa et al., 1992).

Muito embora esses estudos tenham corrigido grandes equívocos quanto à população de jovens em situação de rua, grande parte deles não conseguiu se distanciar suficientemente do discurso ideológico subjacente que lhes impunha as suas hipóteses de trabalho. Rosemberg (1994) argumenta que a visão da família pobre como desorganizada só faz sentido a partir da naturalização do modelo de família nuclear que povoa o imaginário social no Brasil. Segundo Sarti (1995), os processos psicossociais que envolvem as famílias pobres no Brasil assumem características peculiares, diferentes e algo distantes do modelo idealizado de família. Além do mais, é importante ter em conta que essas famílias sustentam redes de sociabilidade em que jovens e crianças são inseridos, criando condições para a sua circulação pela comunidade, estabelecendo certa continuidade entre o espaço da casa, o bairro e a rua. Esta característica da socialização dos jovens e crianças de famílias pobres, somada ao valor que o trabalho assume para eles desde cedo, e à valorização da reciprocidade entre eles e seus pais ou cuidadores, pressiona-os à busca de atividades remuneradas para construir a renda familiar. Há uma forte relação disso com sua forma de experienciar a rua. A rua faz parte de sua socialização.

No entanto, uma operação importante que esses estudos permitiram foi a desmontagem do sistema de crenças que tomava-os como um grupo homogêneo, ao mesmo tempo em que sugeriram os arranjos culturais e históricos como caminhos promissores para o seu entendimento. Com isso, foi acrescentado aos sistemas explicativos desse fenômeno o modelo de modernização realizado em países subdesenvolvidos, o que inclui industrialização e urbanização rápidas e tardias (Aptekar, 1996; Lusk, 1992). Em tempo, também não se pode negligenciar o papel desempenhado pelos próprios jovens em sua saída para a rua (Menezes \& Brasil, 1998), ou seja, a saída para as ruas também pode ser compreendida como uma escolha. Para Vogel e Mello (1996), a vertigem da rua exerce fascínio sobre os que para ela se (des)encaminham. Conforme Aptekar (1996), a literatura tem sugerido que elementos relacionados à saída para a rua vinham sendo pouco explorados, não obstante a sua grande importância, como a cultura particular que localiza cada manifestação deste fenômeno. De modo diferente de fatores que realizam uma força de "expulsão da casa", como a pobreza, outros fatores realizam força atrativa para a rua: a imagem que os jovens fazem da rua e a existência da cultura de rua que lhes serve de referência identitária (Lucchini, 1996a).

Nos últimos anos, novas descobertas dos estudos sobre jovens em situação de rua têm promovido diversas mudanças de posição entre os pesquisadores. O maior interesse por abordagens compreensivas e, conseqüentemente, por inovações metodológicas, é função do reconhecimento da grande complexidade que caracteriza essa população em todos os lugares. Assim como o incremento da discussão sobre ética na pesquisa com esses jovens decorre da reflexão acadêmica sobre as conseqüências da prática e do discurso científicos sobre outras práticas sociais e de intervenção para com eles. Além disso, quaisquer práticas ou políticas públicas voltadas para eles, que levem em conta a homogeneidade de suas "características de grupo", os naturalizará nessa condição e fará deles prisioneiros de um estigma, ou padecerá sob o risco de que eles mesmos não se considerem incluídos entre os grupos-alvo dessas práticas, podendo levar ao fracasso de políticas públicas assim instruídas (o que não tem sido incomum). Portanto, é preciso que pesquisa e 
intervenção com esses jovens considerem as condições materiais e processos de socialização e produção de subjetividade, o regime de interação em que se inserem, os signos com que significam sua existência no mundo.

Um caminho para a realização desse objetivo é a compreensão do espaço da rua em sua natureza social, espaço que oferece recursos físicos à realização de estratégias de sobrevivências desses jovens e, principalmente, recursos simbólicos. Assim, é preciso compreender a rua como um ambiente que comporta e franqueia formas peculiares de socialização e sistemas identitários (Invernizzi, 2003; Lucchini, 2001; Visano, 1990).

O estudo de Gregori (2000) apresenta evidências empíricas de que a acolhida que a rua oferece é mais que um espaço de brincar, trabalhar ou simplesmente estar: "mesmo parecendo paradoxal, essa rua que os nomeia é também um espaço de vivência ordenado e um universo de relações no qual eles encontram lugar - simbólico, identitário e material" (p. 101). Segundo Visano (1990), três fatores articulados na construção e sustentação de seu mundo simbólico são fundamentais à compreensão de sua existência: competência em desempenhar papéis, reações aos outros e identidade. A compreensão desses fatores, desde a perspectiva da socialização, desvela a produção de sentidos de sua experiência e a construção de seu mundo. Ele situa a socialização como sendo de capital importância para o estudo dessa população, na forma como sua situação é experienciada, em sua radicalidade e concretude, constituinte da realidade material e social da vida desses jovens, e manancial de sentidos subjetivantes para eles. Também deve ser útil para instruir o nosso conhecimento acerca de como enfrentar o problema que é a sua exposição e vulnerabilidade no ambiente das ruas.

O estudo dos jovens em situação de rua é apresentado como extremamente difícil por causa de suas características pessoais, sua situação peculiar de desenvolvimento e estratégias de sobrevivência no ambiente das ruas (Aptekar, 1996; Bemak, 1996; Hutz \& Koller, 1999). A atitude de constante suspeição, elemento evidente de suas estratégias de sobrevivência, ou dos padrões de interação que mantêm com todos com quem se encontram na rua - que tendem a repetir nas interações com pesquisadores -, dificulta o trabalho de aproximação a eles, em grupo ou individualmente, dificulta o estabelecimento e manutenção do tipo de relação que interessa à situação de pesquisa, a produção de confiança, prejudicando, inclusive, a qualidade das informações fornecidas por eles (Günther, 1992; Hutz \& Koller, 1999).

A sua complexidade, diversidade e dinâmica, assim como todas as dificuldades de acesso a eles, têm levado os pesquisadores a preferir e recomendar abordagens metodológicas que valorizem o estudo no ambiente de seu cotidiano, por meio de procedimentos muito diversos de geração de dados, fortemente articuladas à opção teórica que sustenta o estudo (Lucchini, 1996b), e que mantenham o vínculo das informações obtidas em cam- po com o ambiente imediato das ruas, com as histórias de vida das crianças e com a cultura em que estão inseridas (Lucchini, 1996a). Conseqüentemente, isso envolve o dispêndio de mais tempo e diversidade de espaços e situações, já que tempo e espaço interferem na qualidade dos dados produzidos. Por isso, diversos estudos etnográficos têm sido realizados (Aptekar, 1988; Diversi, 2006; Gregori, 2000; Hecht, 1998; Invernizzi, 2003; Menezes \& Brasil, 1998), e essa abordagem tem se insinuado como indispensável, tornando-se um importante elemento de um novo paradigma de investigação em estudos com essa população (Bemak, 1996). De fato, a pesquisa etnográfica se qualifica, de muitos modos, como alternativa às necessidades metodológicas e éticas impostas pela pesquisa no ambiente das ruas.

\section{Questões de Método: A Entrada em Campo como Princípio do Relato Etnográfico}

A etnografia, embora seja um método de pesquisa científico e muito embora seja apontada, por tantos pesquisadores, como particularmente útil no estudo desses jovens, devido às suas características muito específicas, é uma prática extremamente idiossincrática (como o atestam, por exemplo, as muitas diferenças entre os relatos de experiência etnográfica acima citados). Além disso, freqüentemente sofre o efeito de diferentes enquadres epistêmicos. Aqui, interessa o enquadre dialógico, em que os regimes de sociabilidade definidos no espaço das ruas também supõem as formas de negociação dos sentidos que identificam personagens, pessoas e grupos no seu âmbito. Ora, o trabalho do pesquisador depende de sua inserção no campo de registro simbólico do grupo que investiga, cujas culturas e práticas sociais ele pretende estudar, e a entrada nesse campo é um aspecto muito importante de sua abordagem.

A reflexão acerca do processo de entrada em campo não tem relevância somente porque diz respeito aos começos de uma pesquisa etnográfica, mas constitui todas as suas partes, comporta diversas fases que atravessam cada pesquisa e influencia a qualidade das pesquisas em diversas dimensões (Maginn, 2007). Parece haver uma relação íntima entre a autenticidade da experiência etnográfica, a entrada em campo e os elementos de sua validade interna, sob a reivindicação - comum no campo dos estudos etnográficos - de que sua prática goza de tempo bastante entre os participantes para a correção de possíveis problemas, porque as entrevistas que essas práticas comportam são mais próximas e menos abstratas do que as técnicas utilizadas em outros tipos de pesquisa, e porque as observações tomam como objeto a realidade das experiências dos participantes das pesquisas (LeCompte \& Goetz, 1982).

A complexidade da experiência etnográfica, função de suas próprias características, cria a necessidade de sensibilidade e certa plasticidade psicológica para o trabalho de campo, tendo em vista que as contingências das redes 
de sociabilidade do campo de pesquisa podem exigir mudança de papéis assumidos pelos pesquisadores, os quais devem manejar o seu próprio posicionamento em campo. Por isso, é desejável que o pesquisador não assuma posições fixas diante da incerteza e complexidade das formas de interação social no campo de pesquisa. É preciso que o pesquisador possa e saiba ajustar o nível de envolvimento a que é demandado em cada situação ( $\mathrm{Li}$, 2008). E, embora não se possa controlar o caráter dessas trocas, é possível realizar o que Harrington (2003) chama de improvisação informada, isto é, o manejo das negociações de sentido pelas quais se constroem representações - pelo pesquisador e pelos participantes tanto das atividades que compõem a própria prática de investigação, como dos cenários e personagens que ela envolve, principalmente no momento de entrada no campo, o que localiza esta pesquisa no enquadre epistêmico que valoriza a reflexividade na prática científica (Hammersley \& Atkinson, 1994). Essa reflexividade implica tomar a experiência etnográfica como um processo de co-construção (Diversi, 2006).

\section{O Artesanato dos Caminhos da Pesquisa}

A etnografia é conhecida como o método cuja essência é observação participante, mas, como aponta Hecht (1998), isso é, na verdade, um oxímoro, pois "participação implica fazer parte dos eventos que se estuda; observação implica descolamento, até invisibilidade" (p. 6); e para além do paradoxo em que se constitui a observação participante, mesmo qualquer um de seus pólos - observação ou participação - está fora das possibilidades de realização concreta do pesquisador. Aquilo que Hecht (1998) acabou construindo como caminho metodológico é de muito interesse, pois sua procura por meios de tornar os jovens com quem trabalhou protagonistas em seu estudo, a abertura que isso implicava, tornou o pesquisador disponível à abordagem desses jovens, à forma como eles ofereceram o caminho metodológico de que ele precisava. E essa é uma virtude de seu estudo que deve ser valorizada.

Também por sua virtude de produzir possibilidades de interação melhor dispostas à investigação etnográfica, uma forma semelhante àquela adotada por Hecht (1998), que parece bastante interessante pela sua simplicidade e adequação ao contexto da rua, é aquela sugerida por Corsaro (2005), sobre a participação em grupos de crianças em pesquisas etnográficas, a entrada reativa. Pensada para facilitar a entrada nas culturas de pares entre crianças, essa técnica se sustenta na idéia de que o pesquisador deve se introduzir entre os grupos como "apenas" uma presença - disponível à sua reação, abordagem e imaginação - despojando-se dos aspectos tipificados e assimétricos de sua aproximação, em seu modus operandi mais comum. Essas características tipificadas certamente desfavoreceriam a participação entre os grupos de jovens em situação de rua, por instaurarem desconfiança sobre os interesses de um estranho em suas atividades. Ora, sabe-se de sua constante atitude de suspeição relativa a adultos que lhes abordam. Além disso, essa é uma modalidade de abordagem compatível com as necessidades de respeito à dignidade desses jovens e à sua competência em produzir sentido sobre as situações de interação e sobre as pessoas com quem interagem.

Os procedimentos planejados para o desenvolvimento do estudo, descrito em seguida, consistiram, além da técnica da entrada reativa, em observação participante, de que fizeram parte também conversas informais com as pessoas de um grupo de jovens em situação de rua e com outros atores daquele contexto - por exemplo, moradores da localidade onde a pesquisa foi realizada, trabalhadores do comércio local, etc. Em seguida, foram incorporadas às práticas de campo entrevistas semiestruturadas sobre temas pré-definidos (percepção da vida na rua, atividades realizadas, percepção das formas de interação entre os diferentes grupos que participavam daquele contexto), com as pessoas do grupo em questão e com os outros grupos do contexto. Por fim, foram produzidas fotografias, cujos temas foram as atividades cotidianas dos grupos estudados, as quais serviram para o registro visual do observado e para facilitar outras entrevistas com os participantes da pesquisa acerca de suas atividades cotidianas. Esses registros visuais foram apresentados ao grupo de meninos para que compusessem falas sobre as impressões de suas próprias imagens e da imagem de seus pares, para servirem de estímulo à produção de narrativas de suas histórias de vida.

Ao longo de todo esse processo, os instrumentos utilizados para a realização dos objetivos foram: (a) três câmeras fotográficas: uma Olympus D-435, uma Nikon Coolpix 7600 e uma Yashica FX-D, com lente acoplada de 50mm; (b) um gravador digital de voz Olympus W10; (c) um diário de campo. Nesse diário de campo eram feitos três tipos de registro: (a) notas de campo, com descrições de observação e impressões sobre os acontecimentos e seu significado, descrições de impressões acerca das percepções do próprio pesquisador, produzidas no trabalho de campo; (b) comentários pré-analíticos a essas notas, produzidos e registrados ainda em campo, com a indicação de vínculo às notas a que faziam referência; (c) memorandos, com o registro de apontamentos analíticos assistemáticos. Também eram indexadas informações sobre o contexto de produção dos registros de voz e fotográficos.

Por fim, o referencial analítico para o estudo das condições de existência e das formas identitárias em que estão implicados os jovens do grupo estudado concerne à possibilidade de interpretação das situações interacionais configuradas no contexto em questão, segundo os princípios anteriormente aludidos, e enfatizando arranjos entre eles e as paisagens urbanas, em sua significação. Por isso, as análises descrevem processos de negociação de sentido, mapeamento das categorias sociais negociadas na interação, na refiguração desses sentidos dispersos pelo ato de sua interpretação. Trata-se, então 
de um estudo orientado teórica e metodologicamente pelas perspectivas interacionista-construcionista e dialógica (Denzin, 1999).

\section{O Relato Etnográfico: A Entrada no Campo}

\section{A Produção de uma Participação: Da Observação à Observação Participante}

Parece-me acertado descrever, ou rememorar o processo de entrada no campo como o processo de produção de uma participação. Isso porque toda a geração de dados, a forma que a experiência contextual assume, da qual se pode extrair conseqüências para o estudo, decorre diretamente das negociações realizadas nesse momento da prática etnográfica. Esta pesquisa foi realizada ao longo de dois meses e meio, desde o início de junho até meados de agosto de 2007. Participou diretamente da pesquisa um grupo de pessoas em situação de rua, cujo número variou em torno de 11 pessoas (por causa da rotatividade no grupo), predominantemente jovens, mas cuja idade variava de 16 a 42 anos (com exceção de três deles, todos os outros tinham entre 16 e 18 anos). Entre eles havia três mulheres; uma delas, mãe de dois meninos e tia de uma menina. Não havia outras relações de parentesco.

$\mathrm{O}$ espaço que circunscrevia a presença do grupo era o de um cruzamento da cidade de Natal-RN, entre duas avenidas importantes, com grande movimento de carros e pessoas. Trata-se de um espaço amplo e pouco favorável à permanência de pessoas. Esse grupo foi indicado a mim por uma cobradora de ônibus. Ela me disse que, fazia muito tempo, eles "moravam" naquele lugar. Esses meninos - a maioria deles, de fato, tem aparência de meninos - passavam o dia inteiro ali, nos canteiros entre as faixas das avenidas, nas calçadas. Lá eles trabalhavam (lavando carros, guardando carros, distraindo as pessoas com malabarismo e pedindo), comiam, dormiam e gastavam a maior parte do seu tempo.

Minhas primeiras aproximações do grupo consistiam, de fato, em uma prática regular de observação, ainda não participante, tendo em conta a estratégia de entrada já aludida. Assim, escolhi um ponto de vista, de onde fazia observações e construía o registro do cotidiano no diário de campo. Desde o primeiro momento em que ofereci minha presença à sua percepção, eles pareceram ter me notado como um acontecimento fora do comum. Em nenhum momento passei despercebido e em diversos momentos pensei que seria abordado por eles. Pouco a pouco, minha presença passou a provocar reações previsíveis e mais discerníveis entre os meninos, ao passo que minha própria permanência naquele lugar ia transformando a minha percepção do setting, que passava de assustador a curioso.

Talvez a descrição do ambiente como assustador pareça forte. Mas era uma impressão construída com a plausibilidade da imagem difundida na cidade, de perigo associado àquele grupo que eu começara a observar. Conversei com diversas pessoas sobre aqueles meninos antes de me decidir a observá-los: com a cobradora do ônibus, com pessoas que eu conhecia e que diziam saber algo sobre aquele grupo de meninos. Frequientemente, todos me diziam do contato deles com drogas e, segundo essa imagem, era corolário de seu contato com drogas a violência do grupo. Outro componente da impressão que tinha dizia respeito às características do próprio ambiente. Em primeiro lugar, a sensação desconfortável de exposição, devida ao fato de que a incomum presença de alguém naquele lugar, onde nada justifica a permanência, atrai olhares. Em segundo lugar, a sensação de que estava em território alheio. Ora, o espaço aberto da rua costuma ser percebido como território de ninguém. Geralmente, as marcas comportamentais da posse territorial não comparecem nas relações entre as pessoas na rua. Mas essas marcas eram ostentadas pelos meninos, no modo despojado de impessoalidade que assumia a sua presença na rua, pelos traços de seu interesse por qualquer acontecimento naquela porção de espaço, pelo tipo de atividade que realizavam na rua (as atividades que comumente se realizam no espaço da casa) e assim por diante.

Desse conjunto de impressões, algumas se tornaram estruturantes do meu esforço de construção de um referencial analítico para a minha estada com eles, inclusive no modo como vieram a se transformar neste momento e posteriormente. Essas impressões, que me serviram de matéria-prima para a construção de um referencial interpretativo de minhas mudanças de posição (Kusenbach, 2003), se constituíram sob o efeito da relação entre a paisagem descrita de sua localização (um cruzamento, um semáforo) e a paisagem discursiva que também os situava (alteridade, risco). O lugar - o cruzamento - parecia completamente deserto de outras pessoas além de mim, dos meninos e de pessoas que não estivessem passando de carro. Seu ambiente é bem peculiar: trata-se de um ponto de fronteira, o final de um bairro, mas que não marca o começo de um outro. Em uma direção, uma das avenidas cruza como que uma fronteira, a do bairro que termina, e situa o final de um trecho de importância econômica, com lojas, bares e supermercados ao longo de sua extensão. $\mathrm{O}$ trecho de sua continuação depois da fronteira é um caminho asfaltado de grande importância viária, por ligar agilmente pontos importantes da cidade, um caminho entre dunas e terrenos vastos, escassamente ocupados. Na direção da avenida que desenha esta fronteira, o que se tem é um caminho ladeado por estes dois espaços: o fim-de-bairro e um espaço-vazio.

Com relação a minha presença entre os meninos, a sua primeira reação foi justamente a curiosidade: tendo percebido a minha presença, em seguida, a minha frequiência constante ao lugar, os meninos passaram a me observar como se se perguntassem o que eu fazia ali, sentado, olhando e escrevendo. A reação seguinte pareceu de incômodo, de modo que minha presença, antes tomada como uma simples presença, passou a elemento perturbador 
do cotidiano do cruzamento, por seu caráter exótico e persistente. Por outro lado, à medida que os registros por mim produzidos já passavam a incluir minha própria presença - isto é, desde que a minha presença passou a ser contada como uma participação na vida do grupo, pelo modo como parecia ser recebida, representada, e pelos efeitos que causava em mim e no grupo -, a tensão e a circulação de sentidos, de parte a parte, chegaram a um ponto crítico. Isso se tornou um marco de minha entrada no campo experiencial do grupo, desde o qual a relação que estava sendo gestada passou a necessitar do contato direto, pela fala, pela mútua apresentação, pela conversa, para que não fugisse a toda possibilidade de alcance e interpretação, para não entrar em colapso.

Um acontecimento curioso me fez perceber isso, numa tarde em que eu estava sentado em uma calçada, fazendo observações e anotações. No momento em que o semáforo naquele cruzamento fechou, um dos meninos, que se dirigia aos carros parados, deteve-se um instante no meio do caminho e me olhou diretamente, aliás lançou-me um olhar, surpreendente. Nesse mesmo momento, um rapaz que passava de bicicleta pelo cruzamento, que também havia parado quando o semáforo fechou, notou o olhar que o menino estava me lançando, e então, também ele me observou e voltou a observar o menino. Não sei exatamente o que pode ter ocorrido, mas, por causa do testemunho deste terceiro - o ciclista - de uma relação tensa entre mim e os meninos, finalmente decidi não mais esperar e me apresentar, e às minhas intenções. O que antes era observação deveria se constituir agora em observação participante.

\section{O Cotidiano dos Meninos e o Nosso: Da Observação Participante à Participação Observante}

Na manhã seguinte a isso, em que havia decidido me apresentar formalmente ao grupo, encontrei-os protegidos da leve chuva que caía, sob um toldo, quase todos reunidos. Eles notavam a minha aproximação e pareciam apreensivos. Perguntei se poderia lhes falar. Tentei contar-lhes sobre a pesquisa de um modo que lhes fosse claro, que a minha intenção era conhecer o cotidiano deles e entender como eles se relacionavam com as outras pessoas dali e com o espaço. Disse-lhes também que isto envolveria a minha presença entre eles para observá-los, conversas com eles e com outras pessoas da vizinhança. Uma das pessoas, que passo a chamar Cosme cujo papel de porta-voz do grupo eu perceberia mais tarde -, tomou a palavra para oferecer uma interpretação de minhas intenções. Ele sugeriu que o que eu queria com eles era conhecer as suas histórias para contá-las às outras pessoas, na faculdade - de onde eu vinha - e em outros lugares. Obviamente, essa interpretação comportava uma série de sentidos que diziam respeito não somente às intenções que eu declarava, mas também acerca de intenções não declaradas, acerca da minha pessoa e do tipo de relação que eu pretendia com o grupo deles. Essa interpretação poderia tornar a minha relação com eles mais pessoal e, por conseguinte, oferecia sentidos às minhas intenções de pesquisa que as transformariam em interesse por "conhecer pessoas" - numa acepção que lhe dá o senso comum -, tornando-as assimiláveis no campo semântico do cotidiano deles. Além disso, por meio dessa interpretação, o grupo se tomava por valorizado no interesse que despertava no outro em que eu me constituía.

Desse modo, aceitei essa interpretação com as suas conseqüências, as quais incluíam uma certa opacidade parcial ao entendimento deles, do sentido que eu dava à minha presença, e também uma certa opacidade - também parcial - ao meu entendimento, do sentido que eles davam a minha presença. Tomei esse acontecimento como uma negociação bem sucedida, não obstante as limitações que dela resultariam, mas com o ganho de outras possibilidades. E, com isso, as mudanças engendradas nessa operação foram diversas e significativas. Quando me apresentei ao grupo os conheci também. Conheci um pouco de sua história, do modo como dão significado à sua experiência de estarem na rua.

Quem me contou a história de como eles chegaram àquele lugar foi uma mulher a que chamarei Maria, a mais velha do grupo, com 42 anos, aquela que é mãe de dois e tia de uma. Ela era negra, vestida com agasalhos naquela manhã algo fria, em que conversamos pela primeira vez. Ela me recebeu para que eu me apresentasse ao grupo (criando uma situação em que eu me senti, de fato, um visitante em um espaço alheio); juntamente com os outros, me ouviu mais atentamente, me fez perguntas e me disse que todos ali se empenhariam em me ajudar quanto ao propósito de minha pesquisa.

Essa solicitude do grupo parecia ser conseqüência de um misto de reciprocidade concernente ao interesse que eu lhes dedicava, alguma curiosidade acerca do que viria a ser essa "pesquisa", e certos traços de uma "cultura da disponibilidade ao outro" - característica das relações interpessoais que aquele grupo mantinha, por exemplo, quando acolhia um outro morador de rua que entrasse no seu território e precisasse de apoio, do mesmo modo como em outros grupos de pessoas em situação de rua, como eu ainda viria a observar mais tarde.

Mesmo assim, cada pessoa do grupo se mantinha, a seu modo, sob certa independência da posição dela, mesmo quando aceitavam o que ela dizia; e ela admitia isso com aquiescência à atitude de alguns deles, alguns poucos que me olhavam à distância, desconfiados. Enquanto contava a história do grupo, ela mantinha uma atitude bem particular, serena e algo risonha, com o ar de uma conversa matinal - o que, de fato, era, muito embora o conteúdo de sua história, em contraste com aquele tom que ela oferecia às suas palavras.

Segundo ela, o grupo estava naquele espaço fazia bastante tempo, mais de 10 anos. Ela não soube informar o tempo exato, por causa das muitas idas e vindas que fizeram parte do itinerário de todos ali, e da história das sucessivas ocupações daquele espaço por eles e outras 
pessoas que viviam nas ruas. Ela contou que aquele grupo já havia se reconfigurado algumas vezes, e que nenhuma das pessoas do grupo que estavam ali naquele momento fazia parte dos primeiros grupos que ela conheceu naquele lugar. Aquele grupo começou a ser ajuntado em outro espaço desse mesmo bairro. Eles se ajuntavam numa praça, nas redondezas da paróquia. Lá eles eram acolhidos por um velho padre que os ajudava a conseguir comida e abrigo, às vezes, e que muitas vezes os protegia do assédio de vigilantes contratados pelos moradores do bairro para os expulsar dali. Durante muito tempo, eles resistiram às tentativas de remoção, até que aquele padre veio a falecer e, com isso, eles perderam sua proteção. Desde então, vinham sendo retirados de lugar em lugar até chegarem a um terreno desocupado, onde construíram barracos, ainda dentro dos limites do mesmo bairro, próximo de onde estávamos. Mas os barracos foram queimados pelas mesmas pessoas que os queriam repelir dali. Eles voltaram a construí-los e foram novamente destruídos, desta vez, por tratores do poder público, que tentava evitar a invasão do ambiente. Nesse meio tempo, segundo Maria, muitas pessoas que compunham o grupo foram embora, desapareceram, morreram ou foram mortos.

Por fim, chegaram ao cruzamento em que estão hoje e nesse lugar foram "aceitos, na medida do possível" (sic). O que "aceitos" significava - segundo Maria - era que, até aquele momento, os moradores mais próximos ainda não haviam tentado expulsá-los, que ainda conheciam algumas pessoas da vizinhança, as quais, vez por outra, lhes ajudavam com algo, de modo que se sentiam tranqüilos. Cosme tomou a palavra para dizer que, mesmo assim, sofrem violência, que às vezes são ameaçados de serem retirados dali, e, por isso, um dia, eles terão que reagir a isso, porque - segundo ele - não podem ser tratados como "cachorro", porque são "gente de rua" (sic). Ele dizia que justamente por esse motivo mereciam respeito.

Notei, com muito interesse, o fato de que nessa expressão de Cosme - gente de rua - era acentuada a primeira palavra, ou, por assim dizer, a primeira dimensão daquilo que nomeava as suas condições de vida. Ora, as expressões que acabam nomeando as pessoas que fazem parte de grupos como aquele - moradores de rua, crianças de rua, etc -, seja no ambiente midiático em geral, seja no ambiente acadêmico, e principalmente entre as expressões cotidianas, acentuam a rua como índice de negatividade. O que Cosme apontou era inusitado para mim porque sua afirmação é a de que justamente porque são "gente de rua" é que merecem respeito, enquanto que todos os outros discursos os situam como dignos de repressão, piedade ou, na melhor das hipóteses, cuidado. Em sua forma de dizer, Cosme não precisou anular o fato de que vivem na rua para fazer menção à sua plena dignidade de "gente", como se precisassem completar essa dignidade pelo efeito de políticas públicas que lhes restituíssem uma parte perdida dela. Em suas palavras não houve ressalvas e, com isso, tecia significados imperativos para a identidade de seu grupo - merecem respeito.

A relação do grupo com os outros moradores dali parecia mesmo reproduzir essa multiplicidade de sentidos, com o que eu me vi, por vezes, confundido. Minhas observações, até aquele momento, confirmavam certa aceitação, pois não havia presenciado conflitos entre aquele grupo e os outros moradores do lugar, e ainda percebi que eles haviam construído formas de facilitar a sua própria permanência por lá. Por exemplo, a sua amizade com os funcionários de um posto de gasolina próximo lhes permitia a possibilidade de usar o banheiro desse posto, e, segundo me contou uma funcionária de lá, ela mesma se encarregou muitas vezes de preparar comidas instantâneas que os meninos levavam até ela. Contudo, também pude notar que, naquele lugar, a sua presença provocou diversas reações de rejeição, às quais as transformações no ambiente desse cruzamento, ocorridas nesse tempo de sua ocupação daquele espaço, davam visibilidade - a desocupação de alguns prédios e a presença ostensiva de cercas elétricas nos muros das casas próximas ao lugar onde ficava o grupo.

Esses traços do modo de existência do grupo naquele lugar se tornavam mais claros à medida que minha participação se aprofundava, à medida que eu era incorporado à paisagem do contexto e em que diminuía a estranheza da minha presença. Aquele rapaz a quem venho chamando Cosme, num certo momento, se ofereceu para favorecer a minha participação junto ao grupo (assumindo o papel de "informante"). Ele passou a me contar as histórias de cada componente do grupo, me falando sobre o temperamento de cada um, sobre os costumes do grupo e me convidando constantemente a tomar parte também em atividades do grupo, como comer, "jogar conversa fora", brincar. Com isso, o regime de interação que passou a configurar minha relação com eles passou a uma outra qualidade. Porque nós passamos a nos cumprimentar, ao longo do dia; espontaneamente, eles me falavam sobre suas opiniões acerca dos acontecimentos ali, ou de uns sobre os outros do grupo. Em princípio, eu participava de seu cotidiano na condição de "visitante". Eles se referiam a mim desse modo quando era necessário vetar um tema ou quando repreendiam alguém por ser descortez em minha presença. E isso constituía os sentidos pelos quais tomavam a minha presença entre eles.

Aos poucos, entretanto, as formas de relação comigo iam se tornando cada vez mais sujeitas a contingências que me deslocavam da posição de "visitante". Aos poucos foram deixando de ser necessários os mútuos cumprimentos, os meninos foram se sentindo mais a vontade para estarem perto de mim; nos esbarrávamos sem nenhum constrangimento, em situações inteiramente corriqueiras. Cada vez mais era como se eu fosse de casa, embora estivéssemos na rua. Foi então que cheguei a presenciar os conflitos que havia entre eles e os outros moradores da localidade e no interior do próprio grupo. 
Tomo como marco de mais uma mudança nas formas de nossa relação, o momento a partir do qual o humor deles passou a afetar o modo como me tratavam. Assim, se "o sinal estava ruim" (o que significava que eles não estavam obtendo dinheiro, ou o tempo era desfavorável, e uma coisa ou outra acarretava mau humor), e eles estavam em um mau dia, não havia problema em "não querer conversa", xingar, sem que isso fosse de qualquer maneira constrangedor para eles.

Desde então, me senti confiante o bastante acerca de certa medida de controle sobre o modo como lhes poderia propor algo novo. Confiante em que minha experiência com eles me daria a conhecer o momento e a situação mais adequada para fazer novas propostas, decidi que era oportuno pedir a eles que me permitissem fotografálos. Eles não concordaram num primeiro momento, numa atitude que me pareceu desconfiada - muito embora, alguns parecessem interessados. (De fato, como fiquei sabendo depois, houve uma vez em que um jornalista pediu para fazer fotografias deles. Eles permitiram e, sem que soubessem, essas fotografias foram para uma matéria que desqualificava a sua imagem). Garanti a eles que sem sua permissão não os fotografaria de modo algum. Mas comecei a fazer algumas fotografias do espaço e dos arredores do cruzamento, inclusive do lugar onde eles dormiam e guardavam as suas coisas, com a permissão deles. Isso lhes pareceu divertido, e, como estavam interessados, perguntei se gostariam de ver as fotografias. Eles vieram, olharam, se divertiram e me disseram que eu os poderia fotografar. Em princípio, posaram para as fotografias e eu lhes disse que as imprimiria e lhes traria. Com isso, eles me disseram que eu poderia continuar.

A empolgação deles com as fotografias começou a gerar uma expectativa nova com relação a minha presença. Eles gostaram muito das fotografias, e conversar sobre elas me permitiu conversar também sobre diversos outros temas. Por exemplo, quando eles diziam que pretendiam levar alguma fotografia para alguém de suas famílias, acabavam falando sobre isso, de modo que um novo patamar de relação se inaugurava mais uma vez. Eles me chamavam de seu amigo. Cosme, que é evangélico, me chamava de irmão.

As fotografias também provocavam chateação, nos momentos em que eles não queriam a perturbação de alguém fotografando enquanto eles tentavam conseguir dinheiro no cruzamento, pois avaliaram que isso poderia assustar as pessoas que lhes dariam dinheiro.

Em todo caso, passaram a fazer parte de nossas relações, um regime de interação mais pessoal, interesse pessoal de parte a parte, e conversas sobre temas mais íntimos. Se em outro momento, boa parte de minha atenção no campo se voltava para a necessidade de construir formas mais pessoais de participação, a partir de então, minha atenção passou a centrar-se sobre a necessidade de não perder de vista o registro dos acontecimentos sob a forma que interessavam ao meu estudo. O que se esboçava era uma experiência de estar sob os efeitos das negociações de sentido realizadas naquele contexto de forma mais engajada e aberta. Eu passava, então, de práticas de observação participante para outras de "participação observante". Passavam a assumir maior relevo os traços vivenciais de minha estada com eles, e todo o esforço pela manutenção da operatividade do referencial interpretativo a partir do qual eu dava sentido a essa experiência se tornou um esforço por sustentar algum distanciamento. Desse modo, o caráter reflexivo de minha prática teve de atingir o seu zênite.

Em seguida, conforme lhes anunciei, eu deveria finalizar a minha estada com eles. O modo como arranjei de fazer isso foi trazendo todas as fotografias que havia feito durante o período em que estive ali, para que pudéssemos conversar sobre elas, para que eles pudessem falar sobre o efeito que elas produziam neles. E lhes pedi que nesse momento eles contassem as suas histórias de vida, para que eu pudesse recontá-las em outro lugar, conforme combinado.

A essa altura de nosso tempo de convivência, os caminhos que haviam assumido as formas de nossa interação davam aos meninos a segurança acerca do meu interesse real em suas histórias e confiança em um certo vínculo emocional, que os deixava a vontade para um relato que poderia ser doloroso, constrangedor e excessivamente íntimo. Esse era, certamente, o momento de maior clareza para eles sobre as conseqüências do que eu lhes pedia que fizessem, expondo as suas histórias, e, por conseguinte, de maior autonomia de seu consentimento. Além disso, esse mesmo tempo de convivência já havia oferecido um conjunto rico de experiências e informações sobre as condições de vida do grupo, sobre os elementos de sua sociabilidade, sobre os sentidos que davam à sua existência, de modo a permitir uma interpretação bem diversificada.

\section{Considerações Finais: O Sentido dos Deslocamentos no Campo de Pesquisa}

O relato dessas mudanças de posição, ao longo da estada entre as pessoas desse grupo, teve como objetivo dar visibilidade aos processos constituintes da entrada em campo, não apenas em seu matiz técnico-metodológico - concernente às dificuldades que as características específicas desse grupo impõem -, mas de duas outras formas também.

Em primeiro lugar, sob o pretexto de que essa visibilidade é constituinte do próprio ato de interpretar a experiência etnográfica, assim como os fenômenos em foco. Ora, as diversas formas de participação em um grupo - e, do mesmo modo, as diversas formas de nãoparticipação - são correlatas não apenas do acesso a diferentes tipos de informação; correspondem também a formas de engajamento que transformam a percepção, submetendo-a a afetações múltiplas e pluralizando as possibilidades semânticas para um mesmo "dado". Essa mobilidade quanto às formas de participação, por conse- 
guinte, é determinante da qualidade da experiência, na medida mesma em que lhe conferem diversidade. Isto porque é na passagem de uma forma de experiência a outra, às quais se relacionam cada uma a um modelo cognitivo que the corresponde, que os mais variados modos de compreensão da mesma realidade vão se corrigindo e ampliando. Pela variação dos pontos de distanciamento, pela multiplicação dos vieses - e não por sua redução! - é que se opera essa correção, o que redunda em autenticidade da experiência, não pela via da verdade da relação, mas pelo caminho da plurivocidade, da polifonia e do diálogo.

Em segundo lugar, dessas formas de participação, mesmo dessas mudanças de posição que fazem parte do processo de entrada em campo, depende a dimensão ética da pesquisa etnográfica. Tomar a construção da pesquisa pelo viés da entrada em campo implica, por parte do pesquisador: (a) pleitear o acolhimento de sua pessoa e de seus interesses entre as pessoas do grupo com quem ele quer pesquisar, nos termos de uma negociação, e na forma pela qual essa operação é apreensível em seus modelos cognitivos, o que demanda tempo e disponibilidade; (b) acolher e produzir a participação dessas pessoas na condição de sujeitos. Ou seja, a entrada em campo se faz pela negociação de sentidos para as ações, as identidades e as representações de alteridade. Os participantes da pesquisa experienciam a condição de sujeito à medida que a sua voz é capaz de transformar ou produzir esses sentidos, e também à medida que é percebida desse modo, com o que se tornam aptos para engendrar os enquadres valorativos em que irão situar o pesquisador, as suas ações e a sua própria identidade diante dele, de modo a influenciar, contundentemente, os sentidos de que o próprio pesquisador deverá lançar mão na construção dos processos investigativos e de sua interpretação.

\section{Referências}

Abdelgalil, S., Gurgel, R. G., Theobald, S., \& Cuevas, L. E. (2004). Household and family characteristics of street children in Aracaju, Brazil. Archives of Disease in Childhood, 89, 817-820.

Aptekar, L. (1988). Street children of Colombia. The Journal of Early Adolescence, 8(3), 225-241.

Aptekar, L. (1996). Crianças de rua em países em desenvolvimento: Uma revisão de suas condições. Psicologia: Reflexão e Crítica, 9(1), 153-184.

Aptekar, L., \& Abebe, B. (1997). Conflict in the neighborhood: Street and working children in the public space. Childhood, 4(4), 477-490.

Barros, R. P., \& Mendonça, R. S. P. (1996). As conseqüências da pobreza sobre a infância e a adolescência. In A. Fausto \& R. Cervini (Eds.), O trabalho e a rua: Crianças e adolescentes no Brasil urbano nos anos 80 (2. ed., pp. 48-55). São Paulo, SP: Cortez.

Bemak, F. (1996). Street researchers: A new paradigm redefining future research with street children. Childhood, 3 , 147-156.
Carrizosa, S. O., \& Poertner, J. (1992). Latin American street children: Problem, programmes and critique. International Social Work, 35, 405-413.

Corsaro, W. (2005). Entrada no campo, aceitação e natureza da participação nos estudos etnográficos com crianças pequenas. Educação \& Sociedade, 26(91), 443-464.

Denzin, N. K. (1999). Interpretative ethnography for the next century. Journal of Contemporary Ethnography, 28(5), 510519.

Diversi, M. (2006). Street kids in Nikes: In search of humanization through the culture of consumption. Cultural Studies - Critical Methodologies, 6(3), 370-390.

Gregori, M. F. (2000). Viração: Experiências de meninos de rua. São Paulo, SP: Cia. das Letras.

Günther, H. (1992). Interviewing street children in a brazilian city. The Journal of Social Psychology, 132(3), 359-367.

Hammersley, M., \& Atkinson, A. (1994). Etnografía: métodos de investigación. Barcelona, España: Paidós.

Harrington, B. (2003). The Social Psychology of access in ethnographic research. Journal of Contemporary Ethnography, 32(5), 592-625.

Hecht, T. (1998). At home in the street: Street children of Northeast Brazil. Cambridge, UK: Cambridge University Press.

Hutz, C. S., \& Koller, S. H. (1999). Methodological and ethical issues in research with street children. New Directions for Child and Adolescent Development, 85, 59-71.

Invernizzi, A. (2003). Street-working children and adolescents in Lima: Work as an agent of socialization. Childhood, 10(3), 319-341.

Juárez, E. (1996). Crianças de rua: Um estudo de suas características demográficas. In A. Fausto \& R. Cervini (Eds.), $O$ trabalho e a rua: Crianças e adolescentes no Brasil dos anos 80 (2. ed., pp. 91-115). São Paulo, SP: Cortez.

Kusenbach, M. (2003). Street phenomenology: The go-along as ethnographic research tool. Ethnography, 4(3), 455-485.

LeCompte, M. D., \& Goetz, J. P. (1982). Problems of reliability and validity in ethnographic research. Review of Educational Research, 52(1), 31-60.

Li, J. (2008). Ethical challenges in participant observation: A reflection on ethnographic fieldwork. The Qualitative Report, 13(1), 100-115.

Lucchini, R. (1996a). The street and its image. Childhood, 3(2), 235-246.

Lucchini, R. (1996b). Theory, method and triangulation in the study of street children. Childhood, 3(2), 167-170.

Lucchini, R. (2001). Carrière, identité et sortie de la rue: la cas de l'enfant de la rue. Déviance et Société, 25(1), 75-97.

Lusk, M. (1992). Street children of Rio de Janeiro. International Social Work, 35, 293-305.

Maginn, P. J. (2007). Negotiating and securing access: Reflections from a study into urban regeneration and community participation in ethnically diverse neighborhoods in London, England. Filds Methods, 19(4), 425-440.

Menezes, D. M. A., \& Brasil, K. C. T. (1998). Dimensões psíquicas e sociais da criança e do adolescente em situação de rua. Psicologia Reflexão e Crítica, 11(2), 327-344.

Paludo, S. S., \& Koller, S. H. (2008). Toda criança tem família: Criança em situação de rua também. Psicologia \& Sociedade, 20(1), 42-52.

Rizzini, I., \& Lusk, M. W. (1995). Children in the streets: Latin America's lost generation. Children and Youth Services Review, 17(3), 391-400. 
Rosa, C., Borba, R., \& Ebrahim, G. (1992). The street children of Recife: A study of their background. Journal of Tropical Pedriatics, 38, 34-40.

Rosemberg, F. (1993). O discurso sobre a criança de rua na década de 80. Cadernos de Pesquisa, 87, 71-81.

Rosemberg, F. (1994). Crianças pobres e famílias em risco: As armadilhas de um discurso. Revista Brasileira de Crescimento e Desenvolvimento Humano, 4(1), 28-33.

Sarti, C. A. (1995). A continuidade entre casa e rua no mundo da criança pobre. Revista Brasileira de Crescimento e Desenvolvimento Humano, 5(1/2), 39-47.

Visano, L. (1990). The socialization of street children: The development and transformation of identities. Sociological Studies of Child Development, 3, 139-161.

Vogel, A., \& Mello, M. A. S. (1996). Da casa à rua: A cidade como fascínio e descaminho. In A. Fausto \& R. Cervini (Eds.), O trabalho e a rua: Crianças e adolescentes no Brasil dos anos 80 (2. ed., pp. 133-150). São Paulo, SP: Cortez. 